\title{
Sleeping Problems Partly Mediate the Association between Victimization and Depression among Youth
}

\author{
Sanna Herkama $\mathbb{D}^{1} \cdot$ Tiina Turunen $^{1} \cdot$ Nils Sandman $^{1} \cdot$ Christina Salmivalli $^{1}$
}

Published online: 22 September 2018

(c) The Author(s) 2018

\begin{abstract}
Being bullied by peers at school is associated with numerous intrapersonal, interpersonal, and health problems. Depression is one of the strongest correlates of victimization and, although it may precede victimization, there is convincing evidence of victimization leading to later depression. Victimization has also been found to be related to sleeping problems, both concurrently and longitudinally. Using structural equation modeling, we tested the hypothesis that the effect of victimization on depression is partly mediated by sleeping difficulties. The mean age of the participants $(N=1717)$ was 16 years, and they were from 20 schools in seven towns in Southern and South-West Finland. We focused on two types of sleeping problemsinsomnia and nightmares - among students who had recently made the transition to secondary education in Finland. We controlled for the effects of sex (girls and others in relation to boys) and school type (high school/vocational school). Besides a significant direct effect of victimization on depression $(\beta=.21, p<.001)$, there were significant indirect effects via both insomnia $(\beta=.04, p=.008)$ and nightmares $(\beta=.03, p=.002)$. The findings suggest that sleeping problems may be indicative of peer victimization, and they are one possible mechanisms via which the effects of victimization on depression unfold.
\end{abstract}

Keywords Being bullied $\cdot$ Depression $\cdot$ Victimization $\cdot$ Secondary education $\cdot$ Sleeping problems $\cdot$ Nightmares

Being bullied by peers at school is known to be concurrently and longitudinally associated with numerous interpersonal and intrapersonal problems such as peer rejection, feelings of loneliness, low self-esteem, and especially depression (Hawker and Boulton 2000; Reijntjes et al. 2010; Salmivalli and Isaacs 2005; Tsaousis 2016), some of these problems persisting into adulthood (Isaacs et al. 2008; Ttofi et al. 2011; Wolke and Lereya 2015). Attention on psychosocial maladjustment of the targeted children and adolescents has been complemented by increasing focus on their physical health (Gini and Pozzoli 2013; Ilola et al. 2016; Nishina et al. 2005; Wolke et al. 2001), including sleeping difficulties (van Geel et al. 2016).

Sanna Herkama

sanna.herkama@utu.fi

1 Department of Psychology and Speech-Language Pathology, University of Turku, Turku, Finland
Globally, much more is known about bullying in middle childhood and early adolescence than among students in their late adolescence. In Finland, the prevalence of bullying is close to average or somewhat below average in international comparisons (e.g. Richardson and Hiu 2016; Walsh and Cosma 2016) - however, such comparisons are exclusively based on data collected from children in basic education (elementary/middle school). In the Finnish education system, the transition to secondary education takes place after nine years of basic education (Grades 1-9; students aged 7-16). In non-compulsory secondary education, students can choose either an academic (high school) or vocational track (vocational school), or a combination of the two leading to graduation in matriculation examination (like high school students) along with a vocational certificate. The current legislation calls upon the providers of secondary education (as well as the providers of basic education) to create a plan to safeguard the students from violence, bullying, and harassment and to monitor adherence to the plan (Pupil and Student Welfare Act 2013). The biennial School Health Promotion Study (2017) by the national Center of Health and Welfare provides some insight into the prevalence of school bullying among students in the 1st and 
2nd grades (i.e., with 16-17 years of age) of secondary education (high school/vocational school) in Finland. With a strict criterion of being bullied once a week or more often, the prevalence of victimization is quite low, $3.3 \%$ among vocational school and $1.1 \%$ among high-school students.

Being bullied creates a considerable risk for the psychosocial well-being of students. Victimized children are especially at risk for depression. Hawker and Boulton (2000) highlighted in their meta-analysis on cross-sectional studies that victims tended to be more depressed than their non-victimized peers, and depression had the highest mean effect size after controlling for shared method variance among all forms of maladjustment measured (range from social anxiety $r=.14$ to depression $r=.29$ ). Also longitudinally victimization has been recognized as a major childhood risk factor uniquely contributing to later depression: According to a meta-analysis including 28 studies, the probability of being depressed later in life (even up to 36 years of age, mean 6.9 years) was nearly twofold for the children being bullied at school than for the non-involved students even after controlling for several childhood risk factors $[\mathrm{OR}=1.74,95 \% \mathrm{CI}=1.54-1.97]$ (Ttofi et al. 2011). Reijntjes et al. (2010) concluded that internalizing problems, such as depression, can be both antecedents and consequences of victimization; however, victimization was found to be somewhat of a stronger predictor of internalizing problems than the other way round.

Like victimization, problems with sleep are also known to have a robust association with depression and also this association may be bi-directional. The most common sleeping problem worldwide is insomnia, which consists of trouble of falling asleep and/or staying asleep. In DSM-V (American Psychiatric Association 2013) insomnia symptoms that occur at least three times a week for at least three months and cause daytime impairment are grounds for a diagnose of insomnia disorder. Insomnia can be an independent disorder but it is often comorbid with other problems, including psychiatric or medical conditions. Occasional insomnia symptoms are common: Worldwide the prevalence estimates range from 4 to $48 \%$ depending on the definition used, with women consistently reporting more insomnia related problems than men (Ohayon 2002). Around $30 \%$ of Finnish adult population report some insomnia symptoms during a one-month period and 5-10\% report frequent insomnia symptoms (Kronholm et al. 2008). The review by Gradisar et al. (2011) indicated that $20-26 \%$ of adolescents self-report sleep latency of more than $30 \mathrm{~min}$, possible sign of insomnia. Large population based studies in Japan (Kaneita et al. 2006) and in Norway (Hysing et al. 2013) also both found that around $24 \%$ of high school students in those countries self-reported frequent insomnia related symptoms.
There is no representative data on the prevalence of insomnia among Finnish secondary education students, but one study with sample collected from a large high school in Finland found that $14.7 \%$ of students aged 16 to 18 reported problems falling asleep and $12.5 \%$ reported frequent nocturnal awakenings (Paavonen et al. 2016). Of the students, $55.1 \%$ also had at least $2 \mathrm{~h}$ difference between their sleep duration during weekend and weekdays, indicating insufficient sleep on weekdays. According to nationwide Finnish School Health Promotion Study (2017), roughly half of the students in secondary education also sleep less than $8 \mathrm{~h}$ per night (vocational school 50.6\%, high school 43\%). These results point to a conclusion, that sleeping difficulties are relatively common among students of secondary education. Insomnia is associated with mental health problems, especially mood disorders like depression (Lichstein et al. 2017) and it is known to have many negative consequences, such as lowered mood and reduced cognitive performance (Fortier-Brochu et al. 2012). It is also a risk factor for the onset of depression (Baglioni et al. 2011) as well as for suicidal thoughts and behavior ( $\mathrm{Li}$ et al. 2010; Liu 2004). Thus, insomnia can be seen both as a result and a cause of problems of psychological and physical well-being.

Nightmares are a less studied but nevertheless quite prevalent problem related to sleep. There is no universally accepted definition for nightmares, but they are commonly characterized as intensive dreams that contain strong negative emotions and wake up the dreamer (American Psychiatric Association 2013). As dreams, and consequently nightmares, are subjective experiences occurring during sleep, it is very challenging to measure them accurately (Sandman 2017; Windt 2013). As a result, the causes and consequences of nightmares are poorly understood. However, in the light of recent epidemiological studies of self-reported nightmare frequency, nightmares are neither uncommon nor clinically insignificant. About 3-5\% of adult population experience frequent nightmares ( $\mathrm{Li}$ et al. 2010; Sandman et al. 2013) with similar prevalence found among adolescents (Munezawa et al. 2011). Frequent nightmares are associated with other sleep problems, lowered quality of life, depression, as well as suicidal ideation and completed suicide (Levin and Nielsen 2007; Sandman et al. 2015, 2017; Sjöström et al. 2007). Recurring nightmares that contain elements or even replicate an actual traumatic event person has experienced (post-traumatic nightmares) are also one of defining symptoms of Post-Traumatic Stress Disorder (PTSD), a condition in which a person experiences symptoms of depression, avoidance of trauma-related stimuli, and re-experiencing of the trauma via intrusive thoughts and post-traumatic nightmares after exposure to a traumatic event (American Psychiatric Association 2013; Phelps et al. 2008). Typical traumatic events triggering PTSD are actual or threatened death, serious injury, or 
sexual violence but also intense bullying could be a trigger for post-traumatic symptoms including nightmares.

Insomnia and nightmares are associated and both of them are connected to symptoms of depression. Therefore, insomnia, nightmares, and depression form a symptomatic triad in which it is hard to distinguish causal relations. There is evidence that insomnia can play a causal role in the development of depression (Baglioni et al. 2011), and while this has not been studied in relation to nightmares, it would be a reasonable hypothesis that they might also precede more serious mental health issues. This makes sleeping problems potential symptoms, risk factors, as well as comorbid conditions for depression. Thus, they form a considerable risk for the well-being and development of youth and may play part in the causal pathway from being victimized to developing symptoms of depression.

In general, there is evidence that being victimized is associated with sleeping problems (Hunter et al. 2014; Tu et al. 2017; Wolke and Lereya 2014). According to a recent meta-analysis by van Geel et al. (2016), including 21 studies, victimized youth (7- to 19-year-olds) were more than twice as likely to report sleep difficulties (e.g. falling asleep, staying asleep, reporting general sleep problems) as their non-victimized peers $[\mathrm{OR}=2.21,95 \% \mathrm{CI}=2.01-2.44]$. The association between victimization and sleeping problems was moderated by age, being stronger among children (younger than 13 years) than among adolescents (13 to 19 years of age). Moreover, the frequency of victimization has been associated with poor sleep quality (e.g., subjective sleep quality, sleep duration, sleep disturbances) regardless of the form (e.g., physical, verbal, relational) of victimization (Zhou et al. 2015). Also, victimized children have been found to have significantly higher probability of having sleeping problems at the end of the school year (OR, 1.91; 95\% CI, 1.09-3.34) as compared with those who were not bullied after controlling for the sleeping problems at the beginning of the school year (Fekkes et al. 2006). In regard to parasomnias, being bullied at the age of 8 or 10 years was found to be associated with nightmares and night terrors (but not with sleep walking) at the age of 12 to 13 (ORs 1.23-1.62) and especially chronic victimization was found to be strongly related both to nightmares and night terrors (Wolke and Lereya 2014). However, the nature of such problems is not always clear as their operationalization varies across studies and in regard to nightmares, previous studies have not examined the nightmare content and bullying making it difficult to distinguish whether bullying provokes post-traumatic or idiopathic nightmares. Some studies have assessed symptoms of insomnia (Due et al. 2005; Sourander et al. 2010) or insufficient sleep (i.e., hours per night at sleep; Hildenbrand et al. 2013; Tochigi et al. 2012), whereas others have asked a more general question about 'sleeping problems' (Fekkes et al. 2006; Fekkes et al.
2004; Kowalski and Limber 2013) that may be interpreted in various ways by the participants. Still, other studies have focused on parasomnias such as nightmares, night terrors, and sleepwalking (Wolke and Lereya 2014). Notably, as the link between victimization and sleeping problems has often been studied in the context of larger projects focusing on a wide variety of health issues, one or both constructs have typically been assessed by a single item. In addition, insomnia and nightmares have been investigated in separate studies (most studies focusing on the former), rather than examined as two separate outcomes of victimization.

In summary, extant literature suggests that victimization is a risk factor for both depression and sleeping problems. In addition, the association of insomnia and nightmares with depression is well established with evidence that at least insomnia may be a risk factor for developing a depression. In the present study, we tested the hypothesis that symptoms of insomnia and nightmares partly mediate the association between victimization and depressive symptoms among adolescents who had recently made the transition to secondary education. Due to previous research indicating that both depression and sleeping difficulties are more common among girls than boys and that high-school students report more symptoms of depression than vocational school students in Finland (Paavonen et al. 2016; School Health Promotion Study 2017), we controlled for the effects of sex and the type of secondary education in the mediation model.

\section{Method}

\section{Participants}

The target sample $(N=1861)$ consisted of all first-year upper secondary school students from eight high schools and twelve vocational schools (the latter belonging to three large vocational institutes) in seven towns in Southern and South-West Finland. Convenience sampling was used when choosing the schools. However, it was ascertained that schools with varying sizes (in terms of numbers of students), from different locations (from smaller and larger towns) as well as with varying academic levels (in case of high schools) and fields of qualification (in case of vocational schools) were included. The students in the final sample $(N=1717), 92,3 \%$ of the target sample, $(50.4 \%$ female, $48.3 \%$ male, $1.3 \%$ other) had started their studies in upper secondary education in August 2016, and 95\% of them were born either in 1999 or 2000, having 16-17 years of age at the time of data collection (mean age 16 years and 4 months). The vocational school students represented various education sectors, including technology, hotel and catering, and social and health services. 


\section{Procedure}

The data collection was part of a larger project "Well-being for upper secondary education". Data were collected online with table, laptop and (in a few cases) tablet computers in a single, approximately 45-minute session during school hours approximately one month after the beginning of the fall semester in September 2016. Two trained research assistants were present in each session, providing instructions and technical assistance. Students created individual passwords to $\log$ in to the questionnaire. They were assured confidentiality of their responses and they provided active, informed consent online before answering the questionnaire. Ethical approval for the study had been obtained from the University of Turku Ethical Board in June 2016.

Due to large number of constructs assessed, a three-form planned missing design (see for more Graham et al. 2006; Little and Rhemtulla 2013) was utilized in order to reduce the burden placed on respondents. Each student responded to about $75 \%$ of all original items: to a set of common items, as well as to two out of three item blocks. It has been argued that with planned missing designs, the data may be more valid and the participants may leave less items unanswered than when answering a full set of items in an extensive questionnaire (Harel et al. 2015). The order of the item blocks was randomized across participants in order to avoid any bias due to ordering of the questions. As the design results in data missing completely at random (MCAR, Little and Rhemtulla 2013), we utilized FIML (full information maximum likelihood) estimation that uses all the data that is available without imputing data.

\section{Measures}

\section{Sex and school type}

All students answered to questions regarding their sex (besides response options $1=$ girl and $2=$ boy, they were allowed to choose $3=$ other $)$ and school type $(1=$ high school, $2=$ vocational school). In order to use sex as an independent variable in the regression model, three dummycoded variables were created, indicating whether a participant was a boy vs. not, a girl vs. not, and 'other' vs. not.

\section{Insomnia}

Two items from modified Jenkins Sleep Questionnaire (Jenkins et al. 1988) translated in Finnish were used to assess symptoms of insomnia. The questions read (in Finnish): "How often during the past four weeks you have had following: Trouble falling asleep / Waking up several times per night?" Answer options were: " $1=$ Not at all, $2=1-3$ nights a month, $3=$ around one night a week, $4=2-4$ nights a week, $5=5-6$ nights a week, $6=$ almost every night." The insomnia scale was calculated as the mean of the item scores $(\alpha=.66)$.

\section{Nightmares}

The frequency of nightmares were assessed with the following question: "How often during the past four weeks have you experienced nightmares? Nightmares are dreams that contain strong unpleasant or scary emotions and they wake you up." The answer options were " $1=\mathrm{I}$ have not seen nightmares during the past month, $2=1-3$ times during the last month, $3=1-2$ times a week, $4=3$ or more times a week."

\section{Victimization}

Victimization was assessed with the revised Olweus Bully/ Victim Questionnaire (OBVQ, Olweus 1996). After being presented with the definition of bullying, emphasizing the repetitiveness and the power imbalance between the bully and the victim, the students evaluated on a 5-point scale (1 $=$ not been bullied, $2=$ once or twice, $3=$ two or three times in a month, $4=$ weekly, $5=$ several times a week) how frequently in the last 2 months they had been targeted by each of the nine forms of bullying presented as separate items. The items were parceled in order to construct a latent victimization variable according to the guidelines of itemto-construct method described in Little et al. (2002). Three items with the highest loadings were used to anchor the parcels, and three items with the next highest loadings were added to the anchors in an inverted order. Finally, three items with the smallest loadings were again added in the original order. Thus, the first parcel (Victimization1) consisted of items describing physical victimization, being threatened, and online victimization, the second parcel (Victimization2) included items describing verbal victimization, having one's possessions taken or broken, and victimization with sexual content, and the third parcel (Victimization3) reflecting social exclusion, rumor spreading, and racist victimization. Confirmatory factor analysis (CFA) using the three parcels as indicators of the latent victimization variable was just identified, with factor loadings varying between .75 and .82 .

\section{Depression}

We used the 13-item revised Beck Depression Inventory (Finnish version by Kaltiala-Heino et al. 1999) to assess depressive symptoms. The students rated each item on a five-point scale ranging from 1 to 5 (wording of the options 
Table 1 Intercorrelations and descriptive statistics of the study variables

\begin{tabular}{|c|c|c|c|c|c|c|c|c|c|c|c|c|c|}
\hline Variable & 1. & 2. & 3. & 4. & 5. & 6. & 7. & 8. & 9. & 10. & 11. & M & $\mathrm{SD}$ \\
\hline 1. Insomnia & - & & & & & & & & & & & 1.97 & 1.05 \\
\hline 2. Nightmares & $.45^{* * *}$ & - & & & & & & & & & & 1.39 & 0.66 \\
\hline 3. Depression1 & $.36^{* * *}$ & $.28^{* * * *}$ & - & & & & & & & & & 1.74 & 0.65 \\
\hline 4. Depression2 & $.55^{* * *}$ & $.36^{* * * *}$ & $.60^{* * *}$ & - & & & & & & & & 1.76 & 0.68 \\
\hline 5. Depression3 & $.44^{* * *}$ & $.33^{* * *}$ & $.67^{* * *}$ & $.66^{* * *}$ & - & & & & & & & 1.81 & 0.66 \\
\hline 6. Victimization 1 & $.06^{*}$ & $.10^{* * *}$ & $.18^{* * * *}$ & $.14^{* * *}$ & $.19^{* * *}$ & - & & & & & & 1.03 & 0.23 \\
\hline 7. Victimization 2 & $.07^{* *}$ & $.14^{* * *}$ & $.17^{* * *}$ & $.14^{* * *}$ & $.14^{* * * *}$ & $.57^{* * * *}$ & - & & & & & 1.06 & 0.30 \\
\hline 8. Victimization 3 & $.11^{* * *}$ & $.18^{* * *}$ & $.23^{* * * *}$ & $.20^{* * * *}$ & $.20^{* * * *}$ & $.62^{* * * *}$ & $.61^{* * *}$ & - & & & & 1.06 & 0.29 \\
\hline 9. School type (vocational) & .03 & $.07^{* *}$ & $-.07^{* *}$ & -.01 & -.03 & .03 & $.05^{*}$ & .02 & - & & & .43 & 0.49 \\
\hline 10. Girl (vs. boys) & $.22^{* * *}$ & $.21^{* * *}$ & $.20^{* * *}$ & $.19^{* * *}$ & $.24^{* * *}$ & -.04 & $-.06^{*}$ & .03 & $-.12^{* * *}$ & - & & .50 & 0.50 \\
\hline 11. Other sex (vs. boys) & $.12^{* * *}$ & $.05^{*}$ & $.14^{* * *}$ & $.12^{* * *}$ & $.10^{* * *}$ & $.07^{* *}$ & $.06^{*}$ & $.06^{*}$ & -.04 & $-.12^{* * *}$ & - & .01 & 0.11 \\
\hline
\end{tabular}

$N=1717 ; * * * p<.001, * * p<.01, * p<.05$

varies across items; higher scores are indicative of more depression). The items were again parceled in order to construct a latent depression variable according to the guidelines by Little et al. (2002). The first parcel (Depression1) consisted of items 2, 6, 8, 9, and 10, the second parcel (Depression2) of items 1, 3, 7, and 11, and the third parcel (Depression3) of items 4, 5, 12, and 13. CFA using the three parcels as indicators of depression was just identified, with factor loadings varying between .77 and .83 .

\section{Data Analyses}

We used SEM modeling to test our hypothesis. Because our data were hierarchical (students nested within schools) in nature, we started by calculating intraclass correlations (ICCs) for all measured variables. This measure indicates the proportions of variance due to school differences. The intraclass correlation for victimization (mean score of all items) was estimated .02 , which indicated that two percent of the total variance in victimization was due to similarity between students in the same schools. The intraclass correlations for depression (mean score of all items), insomnia, and nightmares were $.03, .05$, and .06, respectively. Therefore, relatively little variability in each measure could be attributed to clustering within schools. Next, we tried to use multilevel modeling to analyze our data. There was a problem of nonidentification of the model, most likely because of the small number of clusters. Therefore, we ended up testing our main hypotheses at the individual level. Results are organized into the following sections. First, we present the correlations between the observed variables, including the six parcels. Second, we present the SEM model. As most variables were considerably skewed, the MLR estimator of Mplus 8.0 was used to generate robust standard errors.

\section{Results}

Individual-level correlations and descriptive statistics for the study variables are presented in Table 1 . Being a girl and being of other sex (in comparison to being a boy) were positively associated with depression and both types of sleeping difficulties. Thus, girls and students of other sex were more depressed and had more sleeping difficulties than boys had. In addition, being of other sex (in comparison to being a boy) was positively but weakly associated with victimization, and being a girl (in comparison to being a boy) was negatively but weakly associated with the second victimization parcel indicating a tendency that girls experienced less some types of victimization, and students of other sex were more victimized than boys. School type (vocational) correlated positively with nightmares and the second victimization parcel, and negatively with the first depression parcel. In other words, vocational school students reported more nightmares and some types of victimization than high school students, but high school students reported somewhat more depression symptoms than vocational school students did. School type and being a girl correlated negatively, thus there were more boys than girls in vocational schools, and more girls than boys in high schools. Victimization was positively associated with depression and having nightmares and, more weakly, with insomnia symptoms. Nightmares and insomnia were intercorrelated, and they both were positively associated with depression.

Our main hypothesis was tested with the model depicted in Fig. 1. Depression was regressed on insomnia, nightmares, and victimization, controlling for sex (dummy variables 'girl' and 'other' included in the model, i.e. 'boy' being the reference category), and school type (vocational school). Insomnia and nightmares were regressed on victimization, again controlling for sex and school type. As 
Fig. 1 The tested SEM/ mediation model
Table 2 Effects (standardized coefficients) of the independent variables on the dependent variables

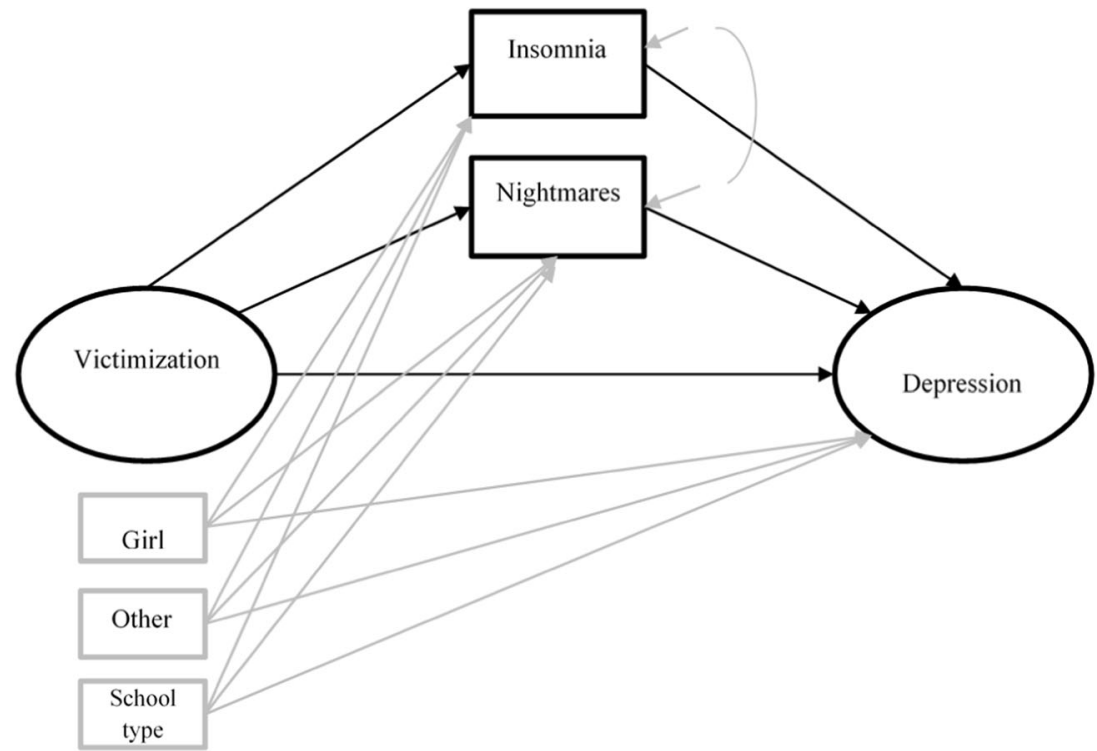

\begin{tabular}{|c|c|c|c|c|c|c|c|c|c|}
\hline \multirow[b]{2}{*}{ Independent variable } & \multicolumn{3}{|c|}{ Depression } & \multicolumn{3}{|c|}{ Insomnia } & \multicolumn{3}{|c|}{ Nightmares } \\
\hline & $\beta$ & SE & $p$ & $\beta$ & SE & $p$ & $\beta$ & SE & $p$ \\
\hline Insomnia & .44 & .03 & $<.001$ & - & & & - & & \\
\hline Nightmares & .14 & .03 & $<.001$ & - & & & - & & \\
\hline Victimization & .21 & .05 & $<.001$ & .10 & .04 & .007 & .18 & .05 & .001 \\
\hline Girl & .14 & .02 & $<.001$ & .24 & .02 & $<.001$ & .24 & .02 & $<.001$ \\
\hline Other & .08 & .04 & .025 & .15 & .04 & $<.001$ & .07 & .03 & .018 \\
\hline School type (vocational) & -.05 & .02 & .012 & .06 & .02 & .011 & .09 & .02 & $<.001$ \\
\hline \multicolumn{10}{|l|}{ Indirect effects } \\
\hline Sum of indirect & .07 & .02 & $<.001$ & - & & & - & & \\
\hline Victimization (via insomnia) & .04 & .02 & .008 & - & & & - & & \\
\hline Victimization (via nightmares) & .03 & .01 & .002 & - & & & - & & \\
\hline
\end{tabular}

suggested by model modification indices, the (residual) correlation between insomnia and nightmares was also included in the model.

The model fitted the data well $\left(\chi^{2}(31)=129.38, \mathrm{CFI}=.97\right.$, $\mathrm{TLI}=.95, \mathrm{RMSEA}=.04, \mathrm{SRMR}=.03)$. The standardized coefficients are presented in Table 2 . Of the control variables, being a girl and being of other sex both predicted sleeping difficulties as well as depression (being a boy as the reference category). The residual correlation between insomnia and nightmares was positive and moderate $(r=.41)$. Victimization had a significant direct effect on depression. There was also a significant indirect effect via nightmares and insomnia.

\section{Discussion}

The association between victimization and depression is well-documented (Hawker and Boulton 2000; Reijntjes et al. 2010; Ttofi et al. 2011). We studied this association among adolescents with 16 to 17 years of age soon after their transition to secondary education (high school or vocational school) and investigated the role of sleep problems mediating this association. We included insomnia and nightmares as two separate variables in our model and controlled for the effects of sex and school type. Our main finding is that besides the significant direct effect of victimization on depression, there is also a significant indirect effect via insomnia and nightmares. One possible explanation to the mediating role of sleep difficulties lies in stress. Victimized students often experience more stress than their non-victimized peers (Vaillancourt et al. 2008) which in turn increases the risk of sleep problems. Because sufficient sleep facilitates recovery and sleep deprivation elevates stress reactions (Banks et al. 2017), it is possible that victimized students end up struggling with stress and sleep 
problems which fuel each other creating a vicious circle leading to symptoms of depression.

The intraclass correlations showed that there was some, although small, school-level variation in the key variables. For instance, the intraclass correlation of victimization was .02 , indicating that $2 \%$ of total variance was between schools. Previous studies in basic education schools in Finland have showed somewhat higher between-school variation in self-reported victimization (up to $5 \%$ of total variance, see Kärnä et al. 2011, 2013). It is possible that in late adolescence, bullying is increasingly selective, and individual characteristics are even more influential determinants of who ends up as victimized.

Our study adds to the existing literature in several ways. First, bullying experiences in secondary education are overall far less studied than bullying in elementary and middle schools. This notion also holds for the association between victimization and sleeping difficulties, which typically has been studied among younger rather than secondary school students (van Geel et al. 2016). Second, although there is emerging evidence of sleeping difficulties being related to victimization, such difficulties have in many studies been assessed by a single item measure. In addition, few studies have concentrated on both insomnia and nightmares in connection to victimization. We differentiated between insomnia and nightmares, which are two separate and quite different, although correlated, problems related to sleep. Our results offer support to the view that insomnia, as well as nightmares, may play part in the pathway from stressful life situation to depression. Contrary to insomnia, there have been no studies about the potential causal connection between nightmares and onset of depression, but in the light of the present findings, this kind of research would be warranted.

\section{Limitations and Future Research Directions}

The limitations of the present study include cross-sectional data and reliance on self-reports in the assessment of all constructs. Due to the cross-sectional design, we cannot make conclusions regarding the direction of the effects. Therefore, the present study must be viewed as the first, preliminary test of the mediating role of sleeping difficulties in the association between peer victimization and depression. It should be noted that we only tested mediation in the statistical sense (testing whether victimization predicts individual differences in sleeping problems, which in turn predict individual differences in depression), not in the temporal sense. A proper test of temporal mediation would require longitudinal data with several assessment points, to investigate whether victimization predicts increases in sleeping difficulties over time, which in turn lead to increases in depression. With the longitudinal data accumulating in our project during the forthcoming years, we will be able to shed more light on how victimization experiences, sleeping difficulties, and depression influence each other over time. Few studies offer support for the hypothesis that the psychosocial maladjustment, such as anxiety and depression, could function as the both antecedents and consequences of victimization whereas problems with physical health (e.g., sleep disturbance) more typically follow victimization (Fekkes et al. 2006; Nishina et al. 2005).

Reliance on self-reports can be seen as problematic for two reasons: as they were utilized in the assessment of victimization, depression, and sleeping difficulties, we cannot rule out the possibility that shared method variance influenced the associations found. Also, self-reports of nightmares and insomnia are indirect ways of measuring the underlying problems and might not reflect the true prevalence of these symptoms. Instead of measuring insomnia as objective problems of falling or staying a sleep and nightmares as experiences during sleep, self-reports measure the cognitive assessment the participant makes of whether he or she experiences these difficulties (Sandman 2017). More objective ways to measure insomnia would be with actigraphs or polysomnography and nightmares could be better assessed with daily logs instead of retrospective questionnaires. However, given the size and nature of the sample, these methods would have been unfeasible. Finally, as we did not collect data on the content of nightmares we cannot tell whether they were of post-traumatic or idiopathic variety.

Further research is needed to fully understand the associations between victimization, sleeping problems, and depression. Sleeping problems seem to be intertwined with victimization and depression in complex ways and they may be a marker for both. Sufficient sleep quality and quantity are important for health and wellbeing and impaired sleep makes individuals more vulnerable to both psychological and physiological threats. Some theories of dreaming posit that dreams serve emotional regulation function with nightmares reflecting problems of coming to terms with negative emotions (Levin and Nielsen 2007) and it is known that traumatic experiences induce nightmares that may last for a long time and cause psychological distress. Whether interventions targeting disturbances of sleep and dreaming would lessen the negative consequences of victimization is an empirical question. The primary concern, however, should be on preventing victimization in the first place.

Funding This study was completed in the context of a project funded by the Finnish Ministry of Education and Culture, "Well-being for secondary education". 
Authors' contributions S.H. was responsible of writing the paper as the lead author, collaborated with the design the study; T.T. analyzed the data, collaborated with the design and writing of the paper; N.S. collaborated with the design and writing of the paper; C.S. collaborated with the design and writing of the paper.

\section{Compliance with ethical standards}

Conflict of interest The authors declare that they have no conflict of interest.

Ethical approval All procedures performed in studies involving human participants were in accordance with the ethical standards of the institutional and/or national research committee and with the 1964 Helsinki declaration and its later amendments or comparable ethical standards. Ethical approval for the study was provided by the University of Turku.

Informed consent Informed consent was obtained from all individual participants included in the study.

Open Access This article is distributed under the terms of the Creative Commons Attribution 4.0 International License (http://crea tivecommons.org/licenses/by/4.0/), which permits use, duplication, adaptation, distribution, and reproduction in any medium or format, as long as you give appropriate credit to the original author(s) and the source, provide a link to the Creative Commons license, and indicate if changes were made.

\section{References}

American Psychiatric Association. (2013). Diagnostic and statistical manual of mental disorders. 5th ed. Washington DC: Author.

Baglioni, C., Battagliese, G., Feige, B., Spiegelhalder, K., Nissen, C., Voderholzer, U., Lombardo, C., \& Riemann, D. (2011). Insomnia as a predictor of depression: A meta-analytic evaluation of longitudinal epidemiological studies. Journal of Affective Disorders, 135(1-3), 10-19. https://doi.org/10.1016/j.jad.2011.01. 011.

Banks, S., Dorrian, J., Basner, M., \& Dinges, D. (2017). Sleep deprivation. In M. H. Kryger, T. Roth \& W. C. Dement (Eds.), Principles and practice of sleep medicine. 6th ed. Philadelphia, PA: Elsevier.

Due, P., Holstein, B. E., Lynch, J., Diderichsen, F., Gabhain, S. N., Scheidt, P., \& Currie, C. (2005). Bullying and symptoms among school-aged children: International comparative cross sectional study in 28 countries. European Journal of Public Health, 15(2), 128-132. https://doi.org/10.1093/eurpub/cki105.

Fekkes, M., Pijpers, F. I. M., Fredriks, A. M., Vogels, T., \& VerlooveVanhorick, S. P. (2006). Do bullied children get ill, or do ill children get bullied? A prospective cohort study on the relationship between bullying and health-related symptoms. Pediatrics, 117(5), 1568-1574. https://doi.org/10.1542/peds.20050187.

Fekkes, M., Pijpers, F. I. M., \& Verloove-Vanhorick, S. P. (2004). Bullying behavior and associations with psychosomatic complaints and depression in victims. The Journal of Pediatrics, 144 (1), 17-22. https://doi.org/10.1016/j.jpeds.2003.09.025.

Fortier-Brochu, E., Beaulieu-Bonneau, S., Ivers, H., \& Morin, C. M. (2012). Insomnia and daytime cognitive performance: A metaanalysis. Sleep Medicine Reviews, 16(1), 83-94. https://doi.org/ 10.1016/j.smrv.2011.03.008.
Gini, G., \& Pozzoli, T. (2013). Bullied children and psychosomatic problems: A meta-analysis. Pediatrics, 132(4), 720-729. https:// doi.org/10.1542/peds.2013-0614.

Gradisar, M., Gardner, G., \& Dohnt, H. (2011). Recent worldwide sleep patterns and problems during adolescence: A review and meta-analysis of age, region, and sleep. Sleep Medicine, 12(2), 110-118. https://doi.org/10.1016/j.sleep.2010.11.008.

Graham, J. W., Taylor, B. J., Olchowski, A. E., \& Cumsille, P. E. (2006). Planned missing data designs in psychological research. Psychological Methods, 11(4), 323-343. https://doi.org/10. 1037/1082-989X.11.4.323.

Harel, O., Stratton, J., \& Aseltine, R. (2015). Designed missingness to better estimate efficacy of behavioral studies-application to suicide prevention trials. Journal of Medical Statistics and Informatics, 3, 2 https://doi.org/10.7243/2053-7662-3-2.

Hawker, D. S. J., \& Boulton, M. J. (2000). Twenty years' research on peer victimization and psychosocial maladjustment: a metaanalytic review of cross-sectional studies. Journal of Child Psychology and Psychiatry, 41(4), 441-455. https://doi.org/10.1111/ 1469-7610.00629.

Hildenbrand, A. K., Daly, B. P., Nicholls, E., Brooks-Holliday, S., \& Kloss, J. D. (2013). Increased risk for school violence-related behaviors among adolescents with insufficient sleep. The Journal of School Health, 83(6), 408-414. >https://doi.org/10.1111/ josh.12044.

Hunter, S. C., Durkin, K., Boyle, J. M. E., Booth, J. N., \& Rasmussen, S. (2014). Adolescent bullying and sleep difficulties. Europe's Journal of Psychology, 10(4), 740-755. https://doi.org/10.5964/ ejop.v10i4.815.

Hysing, M., Pallesen, S., Stormark, K. M., Lundervold, A. J., \& Sivertsen, B. (2013). Sleep patterns and insomnia among adolescents: a population-based study. Journal of Sleep Research, 22 (5), 549-556. https://doi.org/10.1111/jsr.12055.

Ilola, A.-M., Lempinen, L., Huttunen, J., Ristkari, T., \& Sourander, A. (2016). Bullying and victimisation are common in four-year-old children and are associated with somatic symptoms and conduct and peer problems. Acta Paediatrica, 105(5), 522-528. https:// doi.org/10.1111/apa.13327.

Isaacs, J., Hodges, E., \& Salmivalli, C. (2008). Long-term consequences of victimization: A follow-up from adolescence to young adulthood. European Journal of Developmental Science, 2, 387-397. https://doi.org/10.3233/DEV-2008-2404.

Jenkins, C. D., Stanton, B.-A., Niemcryk, S. J., \& Rose, R. M. (1988). A scale for the estimation of sleep problems in clinical research. Journal of Clinical Epidemiology, 41(4), 313-321. https://doi. org/10.1016/0895-4356(88)90138-2.

Kaltiala-Heino, R., Rimpelä, M., Rantanen, P., \& Laippala, P. (1999). Finnish modification of the 13-item Beck Depression Inventory in screening an adolescent population for depressiveness and positive mood. Nordic Journal of Psychiatry, 53(6), 451-457. https:// doi.org/10.1080/080394899427700.

Kaneita, Y., Ohida, T., Osaki, Y., Tanihata, T., Minowa, M., Suzuki, K., ... \& Hayashi, K. (2006). Insomnia among Japanese adolescents: A nationwide representative survey. Sleep, 29(12), 1543-1550. https://doi.org/10.1093/sleep/29.12.1543.

Kärnä, A., Voeten, M., Little, T. D., Alanen, E., Poskiparta, E., \& Salmivalli, C. (2013). Effectiveness of the KiVa antibullying program: Grades 1-3 and 7-9. Journal of Educational Psychology, 105(2), 535-551. https://doi.org/10.1037/a0030417.

Kärnä, A., Voeten, M., Little, T. D., Poskiparta, E., Kaljonen, A., \& Salmivalli, C. (2011). A large-scale evaluation of the KiVa antibullying program: Grades 4-6: evaluation of KiVa antibullying program. Child Development, 82(1), 311-330. https://doi.org/ 10.1111/j.1467-8624.2010.01557.x.

Kowalski, R. M., \& Limber, S. P. (2013). Psychological, physical, and academic correlates of cyberbullying and traditional bullying. The 
Journal of Adolescent Health, 53(1 Suppl), S13-20. https://doi. org/10.1016/j.jadohealth.2012.09.018.

Kronholm, E., Partonen, T., Laatikainen, T., Peltonen, M., Härmä, M., Hublin, C., ... \& Sutela, H. (2008). Trends in self-reported sleep duration and insomnia-related symptoms in Finland from 1972 to 2005: a comparative review and re-analysis of Finnish population samples. Journal of Sleep Research, 17(1), 54-62. https://doi.org/ 10.1111/j.1365-2869.2008.00627.x.

Levin, R., \& Nielsen, T. A. (2007). Disturbed dreaming, posttraumatic stress disorder, and affect distress: a review and neurocognitive model. Psychological Bulletin, 133(3), 482-528. https://doi.org/ 10.1037/0033-2909.133.3.482.

Li, S. X., Lam, S. P., Yu, M. W. M., Zhang, J., \& Wing, Y. K. (2010). Nocturnal sleep disturbances as a predictor of suicide attempts among psychiatric outpatients: a clinical, epidemiologic, prospective study. The Journal of Clinical Psychiatry, 71(11), 1440-1446. https://doi.org/10.4088/JCP.09m05661gry.

Li, S. X., Zhang, B., Li, A. M., \& Wing, Y. K. (2010). Prevalence and correlates of frequent nightmares: a community-based 2-phase study. Sleep, 33(6), 774-780. https://doi.org/10.1093/sleep/33.6. 774.

Lichstein, K. L., Taylor, D. J., McCrae, C. S., \& Petrov, M. E. (2017). Insomnia: epidemiology and risk factors. In M. H. Kryger, T. Roth \& W. C. Dement (Eds.), Principles and Practice of Sleep Medicine. 6th ed. Philadelphia, PA: Elsevier.

Little, T. D., Cunningham, W. A., Shahar, G., \& Widaman, K. F. (2002). To parcel or not to parcel: exploring the question, weighing the merits. Structural Equation Modeling: A Multidisciplinary Journal, 9(2), 151-173. https://doi.org/10.1207/ S15328007SEM0902_1.

Little, T. D., \& Rhemtulla, M. (2013). Planned missing data designs for developmental researchers. Child Development Perspectives, 7(4), 199-204. https://doi.org/10.1111/cdep.12043.

Liu, X. (2004). Sleep and adolescent suicidal behavior. Sleep, 27(7), 1351-1358. https://doi.org/10.1093/sleep/27.7.1351.

Munezawa, T., Kaneita, Y., Osaki, Y., Kanda, H., Ohtsu, T., Suzuki, H., \& Ohida, T. (2011). Nightmare and sleep paralysis among Japanese adolescents: A nationwide representative survey. Sleep Medicine, 12(1), 56-64. https://doi.org/10.1016/j.sleep.2010.04. 015 .

Nishina, A., Juvonen, J., \& Witkow, M. R. (2005). Sticks and stones may break my bones, but names will make me feel sick: the psychosocial, somatic, and scholastic consequences of peer harassment. Journal of Clinical Child \& Adolescent Psychology, 34 (1), 37-48. https://doi.org/10.1207/s15374424jccp3401_4.

Ohayon, M. M. (2002). Epidemiology of insomnia: What we know and what we still need to learn. Sleep Medicine Reviews, 6(2), 97-111. https://doi.org/10.1053/smrv.2002.0186.

Olweus, D. (1996). The Revised Olweus Bully/Victim Questionnaire. Research Center for Health Promotion (HEMIL Center). Bergen, Norway: University of Bergen.

Paavonen, E. J., Huurre, T., Tilli, M., Kiviruusu, O., \& Partonen, T. (2016). Brief behavioral sleep intervention for adolescents: An effectiveness study. Behavioral Sleep Medicine, 14(4), 351-366. https://doi.org/10.1080/15402002.2015.1007993.

Phelps, A. J., Forbes, D., \& Creamer, M. (2008). Understanding posttraumatic nightmares: an empirical and conceptual review. Clinical Psychology Review, 28(2), 338-355. https://doi.org/10. 1016/j.cpr.2007.06.001.

Pupil and Student Welfare Act, Pub. L. No. 1287 (2013). Retrieved from https://www.finlex.fi/fi/laki/ajantasa/2013/20131287?search $\% 5$ Btype $\% 5 \mathrm{D}=$ pika\&search $\% 5 \mathrm{Bpika} \% 5 \mathrm{D}=$ opiskelijahuoltolaki

Reijntjes, A., Kamphuis, J. H., Prinzie, P., \& Telch, M. J. (2010). Peer victimization and internalizing problems in children: a metaanalysis of longitudinal studies. Child Abuse \& Neglect, 34(4), 244-252. https://doi.org/10.1016/j.chiabu.2009.07.009.
Richardson, D., \& Hiu, C. F. (2016). Global data on the bullying of school-aged children. In Ending the torment: tackling bullying from the schoolyard to cyberspace. New York, NY: Report from the UN special representative of the secretary-general on violence against children.

Salmivalli, C., \& Isaacs, J. (2005). Prospective relations among victimization, rejection, friendlessness, and children's self- and peerperceptions. Child Development, 76(6), 1161-1171. https://doi. org/10.1111/j.1467-8624.2005.00841.x-i1.

Sandman, N. (2017). Nightmares: epidemiological studies of subjective experiences ( $\mathrm{PhD}$ Thesis). University of Turku, Turku, Finland.

Sandman, N., Valli, K., Kronholm, E., Ollila, H. M., Revonsuo, A., Laatikainen, T., \& Paunio, T. (2013). Nightmares: prevalence among the Finnish general adult population and war veterans during 1972-2007. Sleep, 36(7), 1041-1050. https://doi.org/10. 5665/sleep.2806.

Sandman, N., Valli, K., Kronholm, E., Revonsuo, A., Laatikainen, T., \& Paunio, T. (2015). Nightmares: risk factors among the Finnish general adult population. Sleep, 38(4), 507-514. https://doi.org/ $10.5665 /$ sleep. 4560 .

Sandman, N., Valli, K., Kronholm, E., Vartiainen, E., Laatikainen, T., \& Paunio, T. (2017). Nightmares as predictors of suicide: an extension study including war veterans. Scientific Reports, 7, 44756 https://doi.org/10.1038/srep44756.

School Health Promotion Study. (2017). Retrieved from https://www. thl.fi/fi/web/thlfi-en/research-and-expertwork/population-studies/ school-health-promotion-study

Sjöström, N., Waern, M., \& Hetta, J. (2007). Nightmares and sleep disturbances in relation to suicidality in suicide attempters. Sleep, 30(1), 91-95. https://doi.org/10.1093/sleep/30.1.91.

Sourander, A., Brunstein Klomek, A., Ikonen, M., Lindroos, J., Luntamo, T., Koskelainen, M., Ristkari, T., \& Helenius, H. (2010). Psychosocial risk factors associated with cyberbullying among adolescents: A population-based study. Archives of General Psychiatry, 67(7), 720-728. https://doi.org/10.1001/a rchgenpsychiatry.2010.79.

Tochigi, M., Nishida, A., Shimodera, S., Oshima, N., Inoue, K., Okazaki, Y., \& Sasaki, T. (2012). Irregular bedtime and nocturnal cellular phone usage as risk factors for being involved in bullying: a cross-sectional survey of Japanese adolescents. PLOS ONE, 7(9), e45736 https://doi.org/10.1371/journal.pone.0045736.

Tsaousis, I. (2016). The relationship of self-esteem to bullying perpetration and peer victimization among schoolchildren and adolescents: a meta-analytic review. Aggression and Violent Behavior, 31(Supplement C), 186-199. https://doi.org/10.1016/j. avb.2016.09.005.

Ttofi, M. M., Farrington, D. P., Lösel, F., \& Loeber, R. (2011). Do the victims of school bullies tend to become depressed later in life? A systematic review and meta-analysis of longitudinal studies. Journal of Aggression, Conflict and Peace Research, 3(2), 63-73. https://doi.org/10.1108/17596591111132873.

Tu, K. M., Spencer, C. W., El-Sheikh, M., \& Erath, S. A. (2017). Peer victimization predicts sleep problems in early adolescence. The Journal of Early Adolescence, 0272431617725199. https://doi. org/10.1177/0272431617725199

Vaillancourt, T., Duku, E., Decatanzaro, D., Macmillan, H., Muir, C., \& Schmidt, L. A. (2008). Variation in hypothalamic-pituitaryadrenal axis activity among bullied and non-bullied children. Aggressive Behavior, 34(3), 294-305. https://doi.org/10.1002/ab. 20240.

van Geel, M., Goemans, A., \& Vedder, P. H. (2016). The relation between peer victimization and sleeping problems: a metaanalysis. Sleeping Medicine Reviews, 27, 89-95. https://doi.org/ 10.1016/j.smrv.2015.05.004. 
Walsh, S., \& Cosma, A. (2016). Bullying: Being bullied and bullying others. In J. Inchley, D. Currie, T. Young, O. Samdal, T. Torsheim, L. Augustson, ... \& V. Barnekow (Eds.), (HBSC) studyInternational report from the 2013/2014 survey (pp. 197-205). Copenhagen, Denmark: World Health Organization Regional Office for Europe.

Windt, J. M. (2013). Reporting dream experience: why (not) to be skeptical about dream reports. Frontiers in Human Neuroscience, 7. https://doi.org/10.3389/fnhum.2013.00708

Wolke, D., \& Lereya, S. T. (2014). Bullying and parasomnias: a longitudinal cohort study. Pediatrics, 134(4), 1040-1048. https:// doi.org/10.1542/peds.2014-1295
Wolke, D., \& Lereya, S. T. (2015). Long-term effects of bullying. Archives of Disease in Childhood, 100(9), 879-885. https://doi. org/10.1136/archdischild-2014-306667.

Wolke, D., Woods, S., Bloomfield, L., \& Karstadt, L. (2001). Bullying involvement in primary school and common health problems. Archives of Disease in Childhood, 85(3), 197-201. https://doi. org/10.1136/adc.85.3.197.

Zhou, Y., Guo, L., Lu, C., Deng, J., He, Y., Huang, J., \& Gao, X. (2015). Bullying as a risk for poor sleep quality among high school students in China. PLoS ONE, 10(3), e0121602 https://doi. org/10.1371/journal.pone.0121602. 